\title{
"ELA SÓ QUER, SÓ PENSA EM NAMORAR": CONSIDERAÇÕES INICIAIS DE PESQUISA SOBRE A PRODUÇÃO DE CORPOS FEMININOS NA REVISTA CAPRICHO
}

\section{"SHE ONLY WANT, JUST THINK IN ROMANCE": INITIAL CONSIDERATIONS FOR RESEARCH ON THE PRODUCTION OF WOMEN'S BODIES IN REVIEW CAPRICHO}

Flávia Mantovani ${ }^{\mathbf{1}}$

\begin{abstract}
RESUMO: As reflexões aqui expostas são parte de uma investigação sobre a Revista Capricho e o sua produção discursiva de corpos femininos. O nosso objetivo é analisar as práticas discursivas pelas quais a Capricho, constrói um padrão de corpo feminino e adolescente, adquirido pela leitora mediante prática de consumo. Sendo um produto da cultura midiática, ela veicula padrões de consumo determinados, uma vez que a mídia é um lugar de poder onde circulam valores e visões de mundo.
\end{abstract}

Palavras-chave: Revista Capricho. Adolescência feminina. Cultura midiática.

\begin{abstract}
The current reflections are part of a research about the Capricho magazine and its discourse about female bodies. Our objective is to analyze the discourse of the Capricho magazine which create a pattern of the female adolescent's body, obtained by the reader through a practice of consume. This product of mediatic culture, sends particular patterns of consume, once the media is a powerful place where the values and sights of the world circulate.
\end{abstract}

Keywords: Capricho magazine. Female adolescence. Mediatic culture.

\footnotetext{
${ }^{1}$ Mestranda em História Social, linha História e Ensino da Universidade Estadual de Londrina.
} 


\section{Introdução}

A Revista Capricho ${ }^{2}$, atualmente editada quinzenalmente pela Editora $\mathrm{Abril}^{3}$, visa atingir o público feminino adolescente, ou seja, meninas de 10 a 20 anos; em conseqüência, seu editorial atenta-se para o agrado deste universo juvenil específico: valendo-se de seus códigos, linguagem e visões de mundo - que, nos salta aos olhos, abarca basicamente assuntos relativos à corpo, beleza e comportamento adolescentes - a Capricho "conversa" com as leitoras, leva até elas, através de suas páginas, texto e imagens que ressaltam padrões de beleza, consumo, comportamento, enfim, uma infinidade de elementos que, juntos, constroem um determinado padrão discursivo sobre a adolescência feminina e suas adjacências.

Considerando, que exista a incidência de um determinado discurso veiculado pela Revista Capricho sobre estas adolescentes, quais seriam os padrões veiculados em suas páginas? Esta revista produz qual, ou quais discursos, e para quem? O presente artigo se propõe a identificar e analisar estes discursos, mais especificamente sobre o corpo destas garotas, isto é, nosso objetivo é analisar a construção discursiva do corpo feminino na Revista Capricho.

Examinar o discurso da Capricho sobre corpo implica, num primeiro momento, considerar a produção destes corpos, na medida em que a revista fala sobre eles; em segundo, levantamos a seguinte hipótese: a de que, através de suas páginas, a Capricho constrói a idéia de que o corpo da garota deve ser atraente para a conquista - haja vista a quantidade notável de assuntos ligados ao corpo, beleza, cosméticos, moda, roupas, acessórios, conquista, namoros, sexo. Ademais, tal interrogação por nós

\footnotetext{
2 Segundo pesquisas realizadas pela Editora Abril, 89\% das leitoras de Capricho são do sexo feminino (fonte: Marplan Consolidado, 2010) sua tiragem quinzenal é de 272.223 exemplares, sendo que destes 89.959 são avulsos, e 83.374 deles destinados a assinantes (fonte; Projeção Brasil de Leitores consolidado 2010); As leitoras concentram-se em sua maioria na região sudeste (56\%), pertencem a classe "B" $(38 \%)$ e "C" $(47 \%)$ e vão de 10 a 19 anos (75\%) Fonte: Marplan Consolidado 2010. Informações retiradas de www.publiabril.com.br. Acesso: 09/06/2011.

3 A Editora Abril, de propriedade do Grupo Abril é, a maior do setor de revistas no Brasil, dado o volume de publicações que faz circular. (MIRA 2003. p. 08).
} 
dirigida às páginas da Capricho a configura, no presente contexto, como um material de pesquisa, isto é, uma fonte histórica e, como tal, deve ser observada juntamente com seu contexto de produção; aqui partimos da premissa de que a Capricho pertence ao gênero revista de consumo, e é produto da cultura midiática.

A ideia de cultura midiática vem tomando forma, sobretudo, a partir da centralidade que, nas ciências humanas, ocupa a cultura enquanto lócus privilegiado de análise e produção de conhecimento; concomitantemente, ocorre a paulatina aceitação da ideia de que a mídia tem se tornado cada vez mais um lugar de poder, um espaço responsável por um grande volume de "bens" simbólicos, ou seja, a mídia veicularia grande parte dos valores, comportamentos, estilos de vida, etc., inscritos em nossa cultura (MOREIRA, 2003, p. 1207). Mais ainda, segundo MOREIRA, estaria em curso um processo por ele denominado "midiatização da cultura", pelo qual expressamos que a circulação de bens simbólicos é mediada pelos aparatos técnicos da mídia, ou seja, neste processo a cultura passa pela mídia e acontece nela, ou por seu intermédio (Ibid., p. 1207). Assim, podemos enunciar uma cultura midiática que, segundo MOREIRA:

tem a ver com determinada visão de mundo, com valores e comportamentos, com a absorção de padrões de gosto e de consumo, com a internalização de 'imagens de felicidade' e promessas de realização para o ser humano, produzidas e disseminadas no capitalismo avançado por intermédio dos conglomerados empresariais da comunicação e do entretenimento, e principalmente por meio da publicidade (MOREIRA, 2003, p. 1208)

Inserindo a Capricho nesta discussão, podemos dizer que ela também veicula valores, comportamentos, padrões de gosto e consumo, enfim, uma visão de mundo específica, como ocorre com todo material midiático. Podemos dizer, em suma, que ela é uma revista de consumo e produto da cultura midiática, e como tal, veicula significados e é responsável por um grande volume de trocas simbólicas. A Capricho seria uma dessas instâncias "produtoras de identidades", neste caso, da adolescente. Segundo Fischer: 
Ora, esse processo de criação de tipos de homens e mulheres, de jovens e crianças, imaginados e vendidos na publicidade e na mídia de um modo geral, quando submetido a uma análise mais rigorosa, acaba expondo não exatamente um mundo apaziguado, mas a manifestação de uma verdadeira batalha pela imposição de determinados sentidos (...) (FISCHER, 1999 , p. 25)

Assim, uma vez que há uma "batalha pela imposição de sentidos" expressa no discurso midiático, é relevante que nos detenhamos sobre os modos de produção das identidades pela mídia. Nesse sentido, a presente pesquisa considera que, nas últimas décadas do século $X X$, ganhou destaque nos meios de comunicação o grupo a que denominamos "adolescentes" que, segundo Fischer, emerge enquanto preocupação em diversos campos, sobretudo, no espaço midiático:

[...] Nos consultórios médicos, nas universidades, nas clínicas psiquiátricas, nas escolas, nas famílias, nas instituições jurídicas, assistencialistas e políticas, nas agências de publicidade, nos institutos de pesquisa e, sobretudo na mídia, o sujeito adolescente é constituído, falado, pensado e colocado na ordem do dia. Seu corpo e sua sexualidade merecem estudos diferenciados, conforme os grupos e classes sociais considerados [...] (FISCHER, 1996, p. 21)

A emergência de um discurso de e para adolescentes, tanto em instituições assistencialistas diversas como na mídia, acontece juntamente com a descoberta, por parte da publicidade, deste grupo enquanto consumidor potencial. Nesse sentido, Fischer considera os anos de 1990 como a década na qual os adolescentes "encontraram uma acolhida espetacular na mídia" e são descobertos como "o novo alvo do mercado, justamente no tempo em que se experimenta o auge da globalização das economias e das culturas" (FISCHER, 1996, p. 21).

Contudo, é necessário ponderar este processo em que os aparatos midiáticos atuam na construção das identidades, primeiro porque, observase, tal construção é arraigada na prática de consumo, ou seja, os hábitos de consumo seriam um dos formadores de identidade; em seguida, porque 
esta dinâmica de construção de identidades não percorre apenas uma direção - a da mídia para o seu público - mas se dá em movimento recursivo, isto é, não apenas a mídia veicula uma imagem do que seria a adolescência, ou juventude, com fins de imposição destes sentidos, mas também o próprio grupo "adolescente" se define e se denomina enquanto tal, com todas as suas características e códigos culturais, próprios da cultura juvenil. Assim, consideramos que a Revista Capricho e, com mais precisão, os editores que a fazem viva, quando da composição das edições, baseiam-se no universo cultural de que partilha sua leitora, a fim de não destoar do que esta espera ler em suas páginas; em suma, ao mesmo tempo em que a Capricho veicula um determinado padrão discursivo sobre a leitora, esta define, através de seus gostos e preferencias, qual será a pauta da revista.

Portanto, pousar o olhar sobre o "corpo atraente" que constrói a Capricho não implica necessariamente na conclusão de que as leitoras simplesmente irão incorporar passivamente este discurso, uma vez que os produtos da cultura midiática têm a capacidade, mas não a garantia, de infundir visões de mundo às leitoras, muito embora seja este o foco principal da presente pesquisa. Muito da bibliografia que abarca os estudos sobre mídia segue a matriz frankfurtiana, segundo a qual, os produtos da mídia seriam fabricados, impressos e distribuídos em processo fabril, o que os configuraria como produtos culturais de massa, compondo a chamada "indústria cultural"4. Aqui, não há pretensão de negar a realidade de que as atividades "culturais" são filtradas pela "indústria cultural"; contudo, consideramos que tal indústria não tem a garantia de impor uma visão de mundo, pois toda leitura é uma prática inventiva, onde o sujeito é visto como um produtor ativo de sentidos. Tal visão tem sido hegemônica no campo dos Estudos Culturais. RAMOS em sua tese "O ensino de história na revista Nova Escola (1986-2002): cultura midiática, currículo e ação docente" considera que "[...] o sujeito passa a ser visto como produtor ativo de sentido, interpretando os materiais midiáticos conforme seus próprios códigos culturais criados em uma formação social determinada, em que

\footnotetext{
4 Para uma discussão mais aprofundada,ver ADORNO, T.; HORKHEIMER, M. Dialética do esclarecimento. Rio de Janeiro: Zahar, 1985.
} 
também pesam sua classe, gênero, idade, religião, profissão e etnia [...]" (RAMOS, 2009, p. 25). Neste sentido, é necessária uma reflexão maior acerca da cultura midiática em que se insere a Capricho, bem como da posição em que ocupa na sociedade a nossa leitora que, abarcando a fase dos 10 aos 20 anos, constitui-se num público adolescente.

\section{Capricho e a Cultura Midiática}

É notável a presença maciça dos meios de comunicação na vida cotidiana, interferindo em nossas escolhas e nossa visão de mundo; parece óbvia a influência que a mídia exerce na sociedade, ou melhor, o papel socializador, educador e mediador cultural que desempenha a mídia parece, por vezes, um fato consumado. Segundo MOREIRA, a mídia "elabora e difunde, mesmo se de uma forma não totalmente intencional e planejada, visões de mundo, sentidos e explicações para a vida e a pratica das pessoas" e, consequentemente, "passa a influenciar sempre mais o seu cotidiano, sua linguagem, suas crenças" (MOREIRA, 2003, p. 1212). O autor nos faz refletir sobre a importância que desempenham os grandes conglomerados empresariais do ramo da comunicação sobre este processo. Para ele as grandes empresas transnacionais da mídia, da publicidade e do entretenimento detêm o privilégio sobre a difusão de valores, comportamentos e modos de vida (Ibid., p. 1207). Esse fato estaria causando um impacto sobre a sociedade e constituindo, em suas palavras, um "sistema midiático-cultural". MOREIRA considera que:

Essas corporações, cujas empresas conjugam televisão, computadores, internet, vídeo, cinema, aparelhos de diversão, eletrônicos, mas também rádios, revistas, outdoors, banners e outras formas de comunicação imagética, sonora e/ou virtual, são agentes sociais poderosos. Elas, mais pelas características de sua atuação social que por sua organização interna ou setorial, parecem estar constituindo um verdadeiro sistema midiático-cultural (MOREIRA, 2003, p. 1207, grifo do autor) 
Diante desta configuração da realidade pelas corporações responsáveis pela mídia, é evidente a transformação pela qual passa a cultura em todos os seus aspectos; "talvez a mais importante dessas transformações seja o fato de que a própria cultura é cada vez mais midiatizada" (MOREIRA, 2003, 1207). Assim, como o autor, validamos este processo por ele denominado "midiatização da cultura", pelo qual expressamos que a circulação de bens simbólicos é mediada pelos aparatos técnicos da mídia, ou seja, neste processo a cultura passa pela mídia e acontece nela, ou por seu intermédio. Neste sentido, argumenta MOREIRA que a midiatização da cultura tem diversas implicações, dentre elas, a de que as criações midiáticas tornam-se, elas próprias, bens culturais ao alcance social. Assim, este contexto onde a mídia alcança vários níveis da vida pública e privada justifica, ainda segundo MOREIRA, a introdução do conceito de "sistema midiático-cultural", do qual resultaria a produção da "cultura midiática".

Este contexto nos permite afirmar que a Editora Abril é um destes grandes conglomerados empresariais da comunicação, e a Capricho, além de uma revista de consumo, um veículo de difusão de determinada visão de mundo, valores, comportamentos. Sendo ela um item de consumo de uma empresa que visa, essencialmente, o lucro, a Capricho agrega o valor de mercadoria, é uma revista de consumo por sua produção e materialidade. Em contrapartida, ela é um produto genuíno da cultura midiática, uma vez que produz visões de mundo presentes em nossa própria cultura, ao mesmo tempo em que atua sobre as práticas culturais de suas leitoras.

Acerca do gênero "revista de consumo" é importante considerar o seu caráter de segmentação, haja vista o grande volume de títulos publicados e disponíveis nas bancas. A Editora Abril mantém inúmeras publicações, dirigidas aos mais diversos segmentos de mercado. MIRA afirma que ela é uma das editoras mais importantes no setor de revistas, dado o volume de títulos e exemplares que faz circular. A editora foi fundada por Victor Civita em 1950, que possuía os direitos legais de publicar as histórias dos personagens Disney no Brasil (MIRA, 2003, p. 29); 
nesta época, tais personagens e suas histórias já eram febre em quase todo o mundo, e deram corpo às primeiras publicações da editora que, ao longo dos anos, foi responsável pela modernização de grande parte do mercado de revistas. Este caráter de "especialização" do mercado de revistas é uma de suas características principais.

Segundo MIRA, uma revista de consumo é mantida pela publicidade, o leitor é visto como um consumidor em potencial pelo editor, que se torna um especialista em grupos de consumos. Segundo a autora, "para sobreviver, uma revista tem de acompanhar rapidamente as mudanças do seu público" (MIRA, 2003p. 11) e a grande fronteira entre estes grupos é o gênero, a geração (ou seja, a faixa de idade) e a classe social; estes três fatores se entrelaçam, e imbricados compõem grupos de consumidores. No caso da Capricho, estamos nos referindo ao público jovem do gênero feminino e de classe média.

Para sua manutenção no mercado a Capricho precisa conhecer os códigos culturais de suas leitoras; para isso, sua equipe editorial conta com especialistas de diversas áreas, como antropólogos, psicólogos, historiadores, médicos, pesquisadores, enfim, "conhecedores" da adolescência feminina e suas peripécias. Sua estratégia consiste justamente na proximidade com a leitora, como se fosse sua amiga íntima, e tivesse com a leitora uma relação estreita e de confiança. Não raramente encontramos em suas páginas palavras amigáveis, em matérias aconselhadoras de várias situações que envolvem corpo e comportamento.

Todavia há ainda uma consideração fundamental para a compreensão da relação da mídia - aqui, a Revista Capricho - com o público, no caso, com a leitora da revista: sua função pedagógica, se pensarmos que o gênero "revista de consumo" já nasce pedagógico, na medida em que quer orientar determinados modelos de "como pensar", de "como ser" e de "como fazer", sempre sob o signo do moderno e/ou do novo (RAMOS, 2009, p. 43). Podemos também pensar a Capricho como material ou estratégia pedagógica seguindo a noção de Rüsen de que existe uma pedagogia informal, tornando o sujeito "aprendiz" nas múltiplas relações interativas que estabelece com o mundo e com os outros, se 
"aprender for entendido, fundamental e genericamente, como processo no qual as experiências e as competências são refletidas interpretativamente" (RÜSEN, 2001, p. 94).

Uma das características atribuídas à revista é a sua capacidade de educar a menina para o meio social, especificando formas de comportamento aceitáveis no grupo. Tais formas de comportamento estão relacionadas com a formação de uma identidade da leitora, que a "determina" mediante a prática de consumo, isto é, a função educativa da Capricho - assim como dos aparatos midiáticos - reside no fato de que ela difunde um padrão de consumo, o qual a leitora apreende enquanto forma de posicionamento pessoal ante a sociedade, mostrando "quem ela é" através do que ela consome: roupas, acessórios, marcas específicas, músicas, bandas, entre outros itens consumíveis difundidos pela revista.

Ao olharmos a Capricho e entendermos que ela compõe o corpo atraente da adolescente através de práticas de consumo, tem várias implicações e, talvez, a mais latente delas seja o fato de que estamos constituindo assim, uma ideia de "adolescência", fortemente relacionada ao consumo. É necessário assim que fundamentemos nossas definições, ainda que difusas, sobre quem é esta adolescente, a fim de haja uma reflexão maior acerca deste grupo e sua historicidade.

\section{Capricho, uma Revista Teen: Adolescência e Consumo}

O portal de publicidade da Editora Abril - Publiabril ${ }^{5}$ - é um o espaço online onde o Grupo Abril expõe as suas marcas com fins publicitários, ou seja, destina-se, ao invés do grande publico consumidor, aos interessados em marketing e propaganda - os anunciantes - através de suas plataformas. Nele encontramos informações sobre cada marca e seus respectivos produtos, bem como o público que atinge - em termos de faixa etária, gênero, classe social, região, etc. Se lá buscarmos informações sobre a Capricho, encontraremos, além do perfil das leitoras, motivos pelos quais,

\footnotetext{
${ }^{5}$ Ver www.publiabril.com.br
} 
segundo a editora, os vendedores de produtos e serviços destinados ao público adolescente deveriam anunciar na revista: afirma-se que "quem precisa falar com os tens, ${ }^{6}$ fala com Capricho", e diz ser uma especialista deste universo, abordando, de maneira informal e objetiva assuntos de seu interesse; é dito ainda, neste portal, que suas páginas "oferecem uma combinação de alto apelo, com uma fórmula que vai ao encontro das necessidades das adolescentes: celebridades + moda $\mathrm{e}$ beleza + comportamento + atualidades + diversão e entretenimento". A partir disto, podemos considerar que adolescência e consumo estão, no discurso da revista, imbricados, uma vez que, como observável, as necessidades das adolescentes são itens ligados a consumo (moda e beleza) ou ao universo midiático, também consumível (entretenimento, celebridades, etc.). Contudo, é preciso problematizar este pensamento de que certas características - por exemplo, o consumismo - são inerentes a esta fase da vida nomeada adolescência.

Nesse sentido, Maria Rita de Assis César desenvolve um estudo sobre a adolescência sob o ponto de vista de que ela não é um dado natural, e sim uma construção social. Para ela, afirmar que a adolescência é uma fase da vida significa desconsiderar o caráter histórico de tal concepção e, ainda, "insistir na manutenção de um modo específico de investigação cientifica que naturaliza ou essencializa seus temas de questionamento" (CÉSAR, 2008, p. 27) Assim, esta concepção de adolescência - deveras ahistórica, extemporânea, que naturaliza a tal fase - segundo ela, viria do positivismo científico do século XIX e de suas derivações, tais como a medicina higienista e a eugenia. Seguindo o princípio metodológico foucaultiano de uma "arqueologia do saber", CÉSAR, buscou historiar as práticas discursivas do campo da psicopedagogia que construíram a adolescência como tal, transformando-a em um "problema", refutando assim a concepção de que esta seria um dado natural, um objeto de estudo destituído de historicidade e mutabilidade ao longo dos tempos e sociedades. Esta postura acaba por questionar a ideia de que a adolescência

6 Abreviatura da palavra inglesa teenager, sinônimo de adolescente, expressão incorporada ao mercado voltado para este público. (ROCHA; PEREIRA, 2009, p. 22). 
seria uma fase de crise e amadurecimento constante, onde o adolescente, a priori sofre com os problemas inerentes a este período de sua existência. Tal linha investigativa reitera a constituição discursiva dos objetos de análise em sua gênese, privilegiando os modos e motivos pelos quais determinados conceitos se constituem enquanto objetos de análise de determinados campos científicos.

Partindo destas considerações, temos que a adolescência surge enquanto conceito no século XIX, sob uma série de condições favoráveis à centralidade do homem enquanto objeto de estudo das ciências humanas; ainda, diz-se que é histórica, pois varia culturalmente, de acordo com o lugar e o tempo em que se insere. Assim, fica vaga a afirmativa de que a adolescência carrega consigo, inerentemente, problemas específicos, como a violência, a sexualidade latente, a inconstância comportamental, a necessidade de autoafirmação perante o mundo, isto é, é questionável a ideia de que a Capricho entende as necessidades das adolescente - moda, beleza, comportamento - diante do fato de ser, a própria adolescência, uma construção social e cultural.

Não obstante, é inegável que a adolescência é um fenômeno social e histórico e, assim, é um lugar de poder, com suas características próprias, embora não naturais. Tais características, são definidas num jogo de discursos que envolvem várias instâncias sociais, sobretudo a mídia. Porém, merece atenção o fato de que os próprios adolescentes se definem, se rotulam, se classificam, a todo o momento, através de atitudes, gostos, preferências musicais, vestimenta, posturas, enfim, através de uma série de práticas onde eles se "posicionam" diante da sociedade.

Sob este ponto de vista, imagina-se que não há uma imposição pela Revista Capricho de uma ideia sobre o corpo da adolescente, mas uma estratégia que considera o que pensa esta adolescente; por esse motivo, como já dito, a revista realiza suas pesquisas de opinião junto ao consumidor, a fim de produzir uma revista que as garotas queiram ler. Assim, podemos deduzir, pelo discurso da revista, que a adolescente, atualmente, preocupa-se com o corpo, e seus cuidados implicam no consumo de cosméticos, além de roupas, acessórios, enfim, vários 
elementos que, além de expressarem os cuidados com o corpo, se configuram enquanto formadores de identidade.

Há, contudo, uma construção discursiva na Capricho, onde o corpo exaltado em suas páginas relaciona-se com a sexualidade, ao passo que, para obter sucesso na conquista, a garota deve adotar uma série de posturas corporais, que incluem vestir-se adequadamente, como nos mostra a matéria cuja chamada é "Reprograme seu coração. Você está mesmo disposta a namorar, certo? Quer descobrir o que está afastando os caras legais de você? Veja o check-list dos pequenos detalhes que fazem a diferença na hora de conquistar um menino" (CAPRICHO, n. 947, 2004). A chamada da matéria, que faz parte de um artigo ainda maior, chamado "Só pego o cara errado" esboça o seu conteúdo, e logo em seguida, a primeira dica: "Cheque seu visual. Sabe quando você nota que tem alguma coisa que não gosta no seu look, mas não sabe definir o que?" (CAPRICHO, n. 947, 2004).

Abordagens como esta são comuns ao longo das páginas; uma das sessões regulares da revista, a de moda, traz sempre a matéria "Aposte ou encoste", onde as roupas e combinações são avaliadas. Esta elege o preto e o rosa como uma boa combinação: "Par perfeito. Depois de uma overdose de desfile e estilo nas semanas de moda, a gente elegeu o rosa e preto como combinação campeã" (CAPRICHO, n. 945, jul/2004). Em duas páginas, há vários corpos expostos, com roupas combinadas e, abaixo deles, os comentários sobre as combinações. Sobre uma delas, há estampado um logotipo com a palavra "sexy". Assim, sutilmente, a Capricho vai ensinando modos de ser e ver o mundo a suas leitoras, esclarecendo o que é "legal" pra vestir, o que é mais sexy, ou como agir em determinados ambientes, e diante de certas situações, por exemplo.

Michel Maffesoli acredita que vivenciamos a "ética da estética". Não se luta mais por um ideal comum em termo políticos, as metanarrativas estão em profunda crise, pois não existe mais a felicidade passada (nostalgia quanto a um passado supostamente glorioso) e nem a do futuro (ideal de emancipação social) e, por esta razão, as pessoas se identificam uma com as outras muito mais a partir das emoções, das sensibilidades, 
dos prazeres que possam advir do presente. O vínculo coletivo é criado na preocupação com o belo, com a aparência, com o mostrar-se, enfim, com a "estetização da existência", o que está ligado diretamente ao consumo daquilo que pode espetacularizar a si mesmo (MAFFESOLI, 2010).

Lipovetsky em a "Era do Vazio" tem a mesma perspectiva, e acrescenta a noção de "personalização", que pode ajudar a explicar o modo de como a revista Capricho mostra em suas páginas a questão do corpo. Para este, nenhuma ideologia política é capaz de inflamar as pessoas no mundo de hoje, bem como a disciplinarização não mais pode ser considerada autoritária. Vivenciamos - diz o autor -, uma época sem projeto histórico mobilizador, sem grupos em que seus integrantes se identifiquem pela política, pela etnia, pela religião, etc.. Surge o narcisismo como "o processo tendencial que leva os indivíduos a reduzir a carga emocional investida no espaço público ou nas esferas transcendentais e, correlativamente, a aumentar as prioridades da esfera privada" (LIPOVETSKY, 2005, XXII). Uma nova forma de individualismo aparece baseada na sensibilidade psicológica, ou na "hipertrofia do ego". Em outras palavras, o sujeito deve estar atento muito mais a si mesmo, deve investir nas questões subjetivas, ao invés de ter um ideal de grupo. Ocorre o culto à espontaneidade, o estímulo para que as pessoas sejam "mais elas mesmas".

Personalização significa que no processo de compor à vontade os elementos de sua independência, aparência, identidade, o sujeito assim procede para ter o que "oferecer" ao Outro. Enfim, a busca do sujeito de ser "ele mesmo", de expressar seus gostos, ou aquilo que o diferencia como ser especial implica na sedução do Outro: "a sedução se tornou um processo geral com tendência a regrar o consumo, as organizações, a informação, a educação, os costumes" (Idem, p. 01). O corpo é locus por excelência da sedução. O corpo, antes considerado uma máquina, agora "deve ser cuidado, amado, exibido" (Idem, p. 13). O coro deve expressar também aquele quem você é, ou ainda, aquele quem você vem se tornando pela tarefa constante de cuidar-se, produzir-se, arrumar-se, modelar-se. 
A personalização de Lipovetsky nos remete a Foucault, quando fala de "tecnologias de si" ou "tecnologias do eu", ou ainda "cuidado de si". No "cuidado de si", o indivíduo, por si mesmo ou com a ajuda dos outros, realiza operações sobre seu corpo e sua alma, pensamento e condutas, se autotransformando, de modo a alcançar certo estado de felicidade, sabedoria ou pureza. O "cuidado de si" é um saber, uma técnica e atenção sobre si enquanto prática constante. Segundo Larrosa, nos passos de Foucault: "É experiência de si, historicamente construída, é aquilo a respeito do qual o sujeito se oferece ser quando se observa, se decifra, se interpreta, se escreve, se julga, se narra, se domina, quando faz determinada coisas consigo mesmo" (LARROSA, 1999, p. 43). Quem cuida de si adequadamente, encontra-se em condições de conduzir-se na relação com o outro. Quem cuida de si, conhece a si, e também os seus deveres e limites nas relações que experiência e que são perpassadas pelo poder.

Na revista, a ideia de personalização ou de cuidado de si pode ser vista, ou seja, existe um discurso que chama a jovem para que seja autêntica, espontânea, "ela mesma", mas a totalidade discursiva da revista (fotos, imagens, legendas, títulos e subtítulos, box, etc.) mostra que "ela deve ser ela" desde que seduza o Outro, no caso, o olhar masculino, e, esta sedução só é possível conforme determinados parâmetros (comportamentos, linguagem, roupas, acessórios, maquiagem, peso, altura, etc.). Portanto, conforme gíria que expressa a personalização, a jovem deve "se achar", sentir-se especial, diferente, o que demanda uma busca, um trabalho constante, de modo a prender, estimular, cooptar o Outro. Assim, a tarefa de construir uma identidade única, de ter personalidade própria, desde que dentro de certos critérios, requer o controle social e não a liberdade de ser. Existe uma forma de disciplinarização mais sutil, porque talvez mais oculta nos enunciados da revista quando diz à jovem que ela é livre para ser quem ela quer ser, mas não menos programada, pensada, já que para construir a "identidade" nestes moldes, nos moldes da sedução, importa muito a estética, e, em consequencia, o consumo daquilo que supostamente agrega ao sujeito a diferença, a autenticidade, o modo de ser fiel a si mesmo. 
A edição da primeira quinzena de abril de 2005 que inaugura o slogan "seja diferente, seja você" deixa claro já na capa a ideia de autenticidade De novo o recurso de uma celebridade para legitimar o discurso que a revista quer transmitir. Para tanto, o uso de imperativos é uma constante em sua linguagem: "Seja autêntica!" é a frase que precede as orientações para a garota "encontrar-se".

A carta do editor chefe na seção "Diário" também define esta noção de "autenticidade", de "ter o seu próprio estilo":

\section{Duas ou três coisas que eu sei sobre você}

- Você preza a autenticidade acima de tudo

- Mas gasta tempo e energia demais tentando ser parecida com os outros. Ou com a imagem que os outros têm de você

- $\quad$ Seu jeito decidido é a sua maior qualidade

- Mas uma crítica, mesmo construtiva, acaba com você.

- $\quad$ Sua maior felicidade é ser ouvida.

- Mas sua voz soa estranha cada vez que alguém te pede uma opinião sobre um assunto que racha a turma em dois.

Cara, não tem jeito. Todo mundo é assim: de um jeito por dentro, na tranquilidade do quarto, mas de outro por fora, quando diz "tchau mãe" e sai pro mundo. Tipo a teoria na prática, normal.

Presta atenção: o que importa nessa história é o tempo que cada um aceita continuar dando um passo pra frente e dois pra trás no caminho que toma para ser alguém diferente. É difícil seguir em frente? É, mas é difícil pra todo mundo, mesmo pros caras que acham que são alguém zoando os outros. Imagino que você já esteja se virando, achando um jeito de se descolar e de neutralizar os manés, mas não custa nada dar uma olhada na entrevista com a Gisele Frade e com as meninas da reportagem que lança o nosso slogan "Seja você. Seja diferente". (CAPRICHO, n. 963, 2005, p.06)

Importante mostrar que o editor, ou seja, a revista, procura empregar uma linguagem simuladora de efeitos de proximidade, intimidade e exclusividade, dirigindo-se diretamente à leitora, tornando a conversa "particular", como se na relação comunicativa só existe a revista e a leitora. A revista diz saber quem sua leitora é ("Duas ou três coisas que eu sei sobre você"); trata a leitora como "você"; usa palavras ou expressões linguísticas próprias do universo juvenil ("Cara, não tem jeito", "zoando", "manés"); chama a leitora para seu enunciado ("Presta atenção") e ressalta que não pode haver resistência ao modo de ser "diferente" que 
supostamente deve-se alcançar $r$ ("É difícil seguir em frente? É, mais é difícil pra todo mundo...").

Aqui, não está explicitado o que de fato significa, para a revista, ser uma pessoa "autêntica". É durante a entrevista com a atriz Gisele Frade que a ideia vai se delineando: "Gisele Frade perde amiga, perde namorado, perde até emprego - mas se recusa a ser outra pessoa que não ela mesma" diz o comentário da entrevista cujo título é "Gisele é uma só", dando a ideia de que a autenticidade reside no fato de ter "opinião própria", não ser "vulnerável", ser sempre a "mesma pessoa" (Idem, p. 19).

A entrevista não aparece no formato pergunta-resposta, mas como um texto só, descrevendo as opiniões da atriz. Vez ou outra aparecem, entre aspas, comentários que ela teria tecido em ocasião da entrevista. 0 texto começa assim: "Ela não usa maquiagem. Pega a primeira roupa que aparece no armário" (mas na capa ela aparece com maquiagem). Em vários momentos a atriz é mostrada como autêntica: "Desde pequena Gisele é pé no chão. Corre atrás do que quer e não muda de personalidade para ganhar ninguém", ou após o relato de um fim de um relacionamento seu, quando diz "A pessoa tem de gostar de mim com eu sou, certo? Eu tenho de gostar de mim como eu sou. Senão vou agir de uma maneira com a qual não concordo, só para agradar o cara. Perco o namorado, mas não perco a personalidade jamais" (Ibid.).

Na reportagem "Fazendo a diferença", o texto inicial é o seguinte:

O mundo anda muito igual? A Pitty não tem berrado "O importante é ser vocêêêêêêêêê" de bobeira. Nestes anos todos a CAPRICHO não esteve ao seu lado de bobeira, levantando sua auto-estima, pedindo para você ser... você.

Mas a gente quer falar mais alto, deixar a coisa mais clara. A partir desta edição, a CAPRICHO lança o slogan "Seja diferente. Seja você", bordão que vai nos acompanhar de modo mais marcante.

Tudo bem ser a "revista da gatinha".

Mas a revista da gatinha diferente, a gatinha que tem estilo próprio.

$\mathrm{E}$, principalmente, a gatinha que está bem com ela mesma. Combinado? Então vamos começar a nossa "campanha" com essa história que você acompanha agora. (CAPRICHO, $\mathrm{n}$. 963, abr/2005, p. 22) 
A matéria é composta por depoimentos de adolescentes que, em algum momento, se sentiram "diferentes", mas conseguiram "se encontrar" aceitando quem são e respeitando seus próprios gostos e preferências. Neste momento, fica mais clara a noção de "estilo" ligada à estética: "No meu prédio eu sou tipo um ET. Eu adoro rock, meu visual é desencanado, odeio salto alto [...]" comenta uma das garotas; "Emilia Aratanha, de 17 anos, é um exemplo de que a diferença nem sempre é vista com bons olhos. E ás vezes pode virar motivo para muita pegação de pé. Tudo porque ela [...] tem os cabelos roxos e só usa roupas pretas" (CAPRICHO, n. 963, abr/2005, p. 24)

Frequentemente a diferença, o "você ser você", a autenticidade, a personalidade, são abordados através das roupas. Podemos inferir que, segundo o discurso da revista, ser "diferente" significa não seguir o padrão, a "modinha". Algumas vezes a diferença aparece em oposição ao estereótipo "patricinha", por exemplo, quando é dito que a determinada garota odeia salto alto, ou gosta e rock. O box que encerra a reportagem apresenta implicações de ser "você mesma":

\section{Se você for você mesma...}

... vai ter muito mais personalidade do que se for se vestir e agir como a maioria das meninas que você conhece. Não vai ser mais uma a se vestir daquele jeito, a usar o cabelo daquele jeito e a falar do jeito que $99 \%$ das garotas fazem.

... vai poder agir naturalmente e não vai ter que ficar planejando o que falar, como se vestir, etc, só para ser aceita pelos outros. (Ibid.)

Percebe-se a todo momento, o discurso da "identidade própria" ou da "personalidade própria". Contudo, ao entender a identidade ou personalidade como uma questão de estética, o que está em jogo, é o olhar do outro. Segundo Bauman, a identidade não é, na contemporaneidade, uma questão privada, na medida em que se procura "ser" em acordo com a expectativa do outro. E ainda: não é algo dado, próprio do sujeito, mas uma tarefa, uma atividade que nunca termina, na medida em que as marcas que simbolizam a identidade são acessórios, produtos, bens, instrumentos, que agregam "valor" ao sujeito e que logo se tornam obsoletos, descartáveis, fora de moda (BAUMAN, 2008). Em outro escrito, Bauman, analisando uma 
revista de moda, entende que "a pessoa é livre (para escolher entre estes seis [looks]" (2011, p. 150). Em outras palavras, uma revista de consumo da mesma tipologia de Capricho, fala de liberdade, autenticidade, mas desde que esta autenticidade seja construída conforme determinados parâmetros: "É preciso assumir a responsabilidade: a escola é sua, mas fazer escolhas é obrigatório, e os limites do que é permitido escolher não são negociáveis" (Idem). Mais uma vez o autor argumenta, que o "júri do estilo", o outro, determina se o sujeito está do lado certo, e, "cuja aprovação ou rejeição traça a linha entre sucesso e fracasso" (Idem, p. 149): "a referência a estar e ficar à frente desse júri do estilo promete pertencimento" (Idem). A sensação de pertencer a um grupo, significa sentir-se seguro.

Assim, percebemos que, em vários momentos, a revista chama a jovem para ser "ela mesma", mas, ao mesmo tempo, apresenta modelos, padrões a serem seguidos. O corpo exposto pela Capricho não deixa de ser pré-determinado na medida em que, para ser "autêntica" e ter o seu próprio "estilo" a leitora deve se preocupar em diferenciar-se do grupo no que diz respeito, sobretudo, ao que veste. A matéria chama a leitora para ser ela mesma, mas o restante da revista expõe o seu padrão de corpo, não muito diferente ao longo das propagandas, das notícias de famosos, nos testes, enfim, em todo o restante da revista. Uma das características deste corpo evidenciado pela revista é de que ele pressupõe hábitos de consumo específicos, de produtos que agregam a jovem o "estilo autêntico".

Se observarmos a excessiva exposição de corpos que a Capricho promove, bem como de mercadorias ligadas a eles, principalmente roupas, sapatos, acessórios e maquiagem, e não só isso, mas também a forma que este material faz esta exposição, abrir-se-ão possibilidades de pensar a normatização e padronização dos corpos femininos, que as garotas conseguem mediante a prática de consumo. 


\section{Considerações Finais}

O título deste artigo é refrão da música "Xote das meninas"7 de autoria de Luiz Gonzaga; nela, o músico descreve a transição de uma menina, provavelmente do sertão nordestino, da fase infantil para a adolescência. Além dos dizeres "ela só quer, só pensa em namorar", a letra diz que a menina enjoou da boneca, só quer meia comprida e vestido bem cintado. Diante de tal situação, o pai da garota a leva ao "dotô a filha adoentada" que não pensa em mais nada.

Este retrato da menina que assiste o florescimento de sua mocidade, descrito pela canção, é uma representação já cristalizada de adolescência feminina: a garota passa por mudanças corporais e vê-se diante de sua sexualidade, ao mesmo tempo em que começa a se preocupar com seu corpo, no sentido de querer, nesta fase da vida, embelezar-se, sempre pensando em uma vida "amorosa", em suas relações com o sexo oposto. É neste universo que, com muito respeito ao autor já consagrado da música brasileira, queremos adentrar: enxergar além das representações de adolescência feminina que concebem a garota desta faixa etária como naturalmente sexualizada e preocupada com um corpo atraente.

Contudo, negar a existência da adolescência enquanto um grupo com suas características próprias seria negligenciar os arranjos de poder que a constituem enquanto grupo específico. Nesse sentido, Michel Foucault nos incita a repensar nossos objetos de pesquisa, atentando para o fato de que os discursos que são "raros, isto é, não são óbvios, estão para além das coisas dadas" (FISCHER, 2003, p. 372). Nesse sentido, pensar a produção discursiva do corpo feminino na Revista Capricho vai muito além de classificações sobre a adolescência - ou mesmo a sua recusa - é uma reflexão muito mais complexa sobre esta fase da vida tão discutida em vários lugares por tantos especialistas. Assim, a Capricho nos dá possibilidades de pensar estas questões, uma vez que a mídia é um dos espaços em que estes discursos sobre a adolescente e seu corpo aparecem.

\footnotetext{
7"Xote das Meninas" de autoria de Luiz Gonzaga e Zé Dantas, disponível em <www.luizgonzaga.mus.br> Acessado em 12/04/2011.
} 


\section{Referências}

BAUMAN, Z. A sociedade individualizada: vidas contadas e histórias vividas. Trad. José Gradel. Rio de Janeiro: Zahar, 2008.

CÉSAR, M. R. de A. A constituição da adolescência como um "problema" in CESAR, Maria Rita de Assis. A invenção da adolescência no discurso psicopedagógico. São Paulo: UNESP, 2008.

FISCHER, R. M. B. Adolescência em discurso: mídia e produção de subjetividades - Porto Alegre: UFRGS / FACED, 1996. Tese (Doutorado) Universidade Federal do rio Grande do Sul. Faculdade de Educação. Programa de Pós-Graduação em Educação.

- Foucault revoluciona a pesquisa em educação? Perspectiva, Florianópolis, v. 21, n. 02, p. 371-389, jul./dez. 2003.

- Identidade, cultura e mídia: a complexidade de novas questões educacionais na contemporaneidade. In SILVA, L. H. da. Século XXI: Qual Conhecimento? Qual currículo? Petrópolis: Editora Vozes, 1999.

MAFFESOLI, M. Saturação. Trad. Ana Goldberger. São Paulo: Iluminuras; Itaú Cultural, 2010.

MIRA, M. C. O leitor e a banca de revistas. A segmentação da cultura no século XX. São Paulo, Olho D'Água/Fapesp. 2003.

LARROSA, J. Tecnologias do Eu e Educação. In: SILVA, T.T. (Org.). O sujeito da Educação: estudos foucaultianos. Petrópolis, Rio de Janeiro: Vozes, 1999.

LIPOVETSKY, G. A era do vazio. Ensaios sobre o individualismo contemporâneo. Trad. Therezinha Monteiro Deutsch. Barueri, SP: Manole, 2005.

MOREIRA, A. da S. Cultura midiática e educação infantil. Educação \& Sociedade, Campinas v. 24, n. 85, p. 1203-1235, dez. 2003.

RAMOS, M. E. T. O ensino de história na revista Nova Escola (1986-2002): cultura midiática, currículo e ação docente /Tese (Doutorado em Educação) Universidade Federal do Paraná, Programa de Pós-Graduação em Educação, Curitiba, 2009.

ROCHA, E.; PEREIRA, Cl. Juventude e consumo. Um estudo sobre a comunicação na cultura contemporânea. Rio de Janeiro, Mauad X, 2009.

RÜSEN, J. História Viva. Teoria da História III: formas e funções do conhecimento histórico. Trad. Estevão de Rezende Martins. Brasília: Editora Universidade de Brasília, 2001. 
Fontes analisadas e/ou citadas: Revista Capricho, Editora Abril. Julho/2004 - Fevereiro/2006. 